
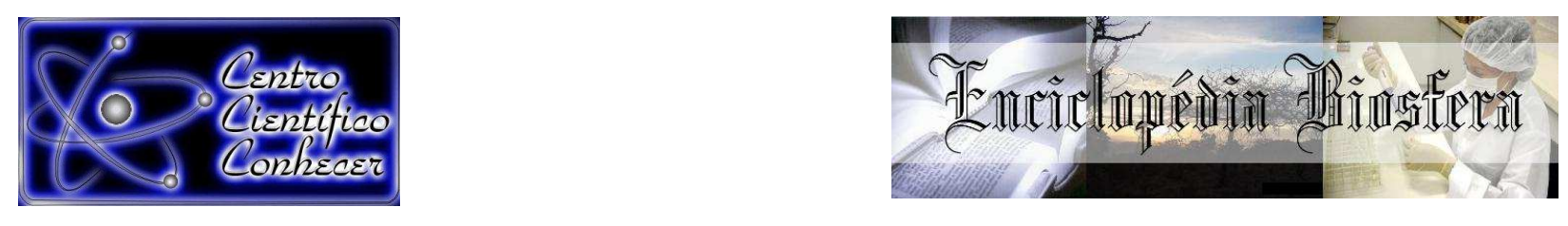

\title{
DESENVOLVIMENTO HISTO-ANATÔMICO CAULINAR DE Annona Squamosa L. (Annonaceae) SUBMETIDAS A DIFERENTES PROCESSOS DE SUPERAÇÃO DE DORMÊNCIA
}

Igor Araújo de Souza', Bruno Araújo de Souza¹, Oriales Rocha Pereira²

${ }^{1}$ Acadêmicos do curso de Ciências Biológicas, Universidade do Estado de Mato Grosso, Campus de Nova Xavantina (igor.araujo@outlook.com.br)

2 Professora Mestre da Faculdade de Ciências Agrárias, Biológicas e Sociais Aplicadas, Universidade do Estado de Mato Grosso

Recebido em: 08/04/2017 - Aprovado em: 10/06/2017 - Publicado em: 20/06/2017 DOI: 10.18677/EnciBio_2017A36

\begin{abstract}
RESUMO
Annona squamosa L. apresenta dormência na germinação de suas sementes e métodos de superação de dormência auxiliam no desenvolvimento do processo germinativo dessa espécie. Tal processo é a chave na organização e dinâmica do estabelecimento dos tecidos no corpo da planta e, estudos histológicos são indispensáveis para a compreensão dessa organização tecidual. Este trabalho teve o objetivo de verificar a estruturação dos tecidos do caule de $A$. squamosa L., como número de camadas de células das regiões de córtex e medula e, diferença na espessura dessas regiões sob cinco tratamentos de superação de dormência conduzidos em casa de vegetação do viveiro da UNEMAT, sendo tratamento 1controle, 2- imersão em água durante seis horas, 3- imersão em água por 24 horas, 4 - escarificação mecânica e 5-imersão em ácido sulfúrico. A coleta do material vegetal ocorreu após 60 dias de germinação. Nesse material foram efetuados cortes histológicos a mão livre, esses foram analisados em microscópio óptico em aumento de 40 vezes (ZEISS-JENEMED2), com as imagens capturadas com câmera SAMSUNG (GT-19300). Foi verificada diferença entre o número de camadas de células compondo córtex e medula do caule dos indivíduos analisados, mas quando se comparou por meio de análise estatística de variância ANOVA, com teste de Tukey a $5 \%$ de probabilidade, a espessura dessas regiões entre os cinco tratamentos, não houve diferença significativa, o que pode ter sido influenciado por fatores abióticos, podendo ser uma resposta das plantas aos fitorreguladores dependente de fatores genéticos e ambientais, refletindo um alto espectro de plasticidade fenotípica.
\end{abstract}

PALAVRAS-CHAVE: Estudos histológicos, região de córtex, região de medula.

\section{DEVELOPMENT CAULINE HISTO-ANATOMIC OF ANNONA SQUAMOSA L. (ANNONACEAE) SUBMITTED TO DIFFERENT PROCESSES OF DORMANCY OVERCOMING}

\footnotetext{
ABSTRACT

Annona squamosa L. presents dormancy in the germination of its seeds and methods of dormancy overcoming minister the development in the germination ENCICLOPÉDIA BIOSFERA, Centro Científico Conhecer - Goiânia, v.14 n.25; p.382 2017
} 
process. Such process is the key in the organization and dynamic establishment of the flesh in the plant's body and histologic studies are indispensable for the comprehension of this flesh organization. This work has objectified to verify the flesh structuration from the stem of $A$. squamosa $\mathrm{L}$., as the number of cell layers from the cortex and marrow region and, difference in the thickness of these regions by five treatments of dormancy overcoming conducted in the vegetation house from UNEMAT's vivarium. Being treatment 1 - control, 2- immersion in water during 6 hours, 3- immersion in water by 24 hours, 4- mechanic scarification and 5- immersion in sulphuric acid. The collect of the vegetal material occurred after 60 days of germination. In this material have been accomplished histologic cuts by free hand, those they have been analysed with optic microscope 40 times increase (ZEISSJENEMED2), the captured pictures were done by the camera SAMSUNG (GT19300). It was verified the difference among the numbers of cell layers compounding cortex and stem marrow from the individuals analysed, but once compared by statistics analysis of ANOVA variance, with the Turkey test in $5 \%$ of probability, the thickness in those regions among 5 treatments, there was no significant difference, which might have been influenced by abiotic factors, it may be an answer of the plants to the phytoregulators genetic factors dependent environmental, reflecting in a high spectrum of phenotypic plasticity.

KEYWORDS: Histologic studies, cortex region, marrow region.

\section{INTRODUÇÃO}

Annona squamosa L. é cultivada em vários países de regiões tropicais e subtropicais (LEMOS, 2014; NETO et al., 2014). É conhecida pela qualidade alimentícia de seus frutos e pelo alto potencial medicinal (BATAGLION et al., 2015) portanto, apresenta altas perspectivas para o comércio. Desenvolvendo-se bem em regiões que apresenta clima mais quente (BRAGA SOBRINHO, 2014; SÃO JOSE et al., 2014).

As sementes dessa planta possuem substâncias que agem de maneira inibidora, provocando, assim, a dormência. Tais substâncias, associadas a um tegumento resistente e impermeável, resultam em fatores que interferem para que a germinação ocorra de forma rápida e uniforme (MENEGAZZO et al., 2012; GALINDO et al., 2012). Assim, métodos de superação de dormência auxiliam no desenvolvimento germinativo dessa espécie, como por exemplo, escarificação química e mecânica (MENEGAZZO et al., 2013). Esse processo germinativo é um mecanismo importante para a planta, já que pode fazer a planta se desenvolver de maneira mais acelerada (TAIZ \& ZEIGER, 2013). E, deste modo, tal processo é a chave na organização e dinâmica do estabelecimento dos tecidos no corpo da planta, advindos de tecidos meristemáticos, sendo esse processo muitas vezes influenciado por fatores externos, podendo estes ser inibidores ou aceleradores desse desenvolvimento (RAVEN et al., 2014).

CUNNINGHAM (2000) afirma que os órgãos dos vegetais estão sujeitos a transformações morfo-histológicas. Tal fato pode ser resultado de diversas alterações no funcionamento ecológico e as modificações antrópicas do ambiente nas relações impostas pelo homem. Frente a todas as inter-relações planta ambiente, é preciso ressaltar que toda planta tem um ciclo de vida, que compreende as modificações que o organismo sofre para garantir a sobrevivência no habitat ao qual está inserido sob influência dos fatores morfogenéticos que alteram a forma e a estrutura dos vegetais (RIZZINI, 1997). 
Apesar de vários estudos realizados com diversas plantas comprovarem que o processo de dormência e a quebra influencia diretamente no crescimento de uma planta (ATAÍDE et al., 2013; CAMPOS et al., 2015; VASCONCELOS et al., 2015), há poucos trabalhos realizados com $A$. squamosa L. (FREITAS et al., 2013; NETO et al., 2013; SANTOS et al., 2014; BAGATIM et al., 2016). Portanto, este trabalho teve como objetivo verificar a estruturação dos tecidos do caule de $A$. squamosa L., descrevendo o formato celular e o número de camadas de células presentes nas regiões de córtex e medula e, analisando a espessura dessas regiões entre indivíduos dos cinco tratamentos de superação de dormência.

\section{MATERIAL E MÉTODOS}

O experimento foi conduzido no viveiro florestal da UNEMAT, Campus de Nova Xavantina - MT (Figura 1).
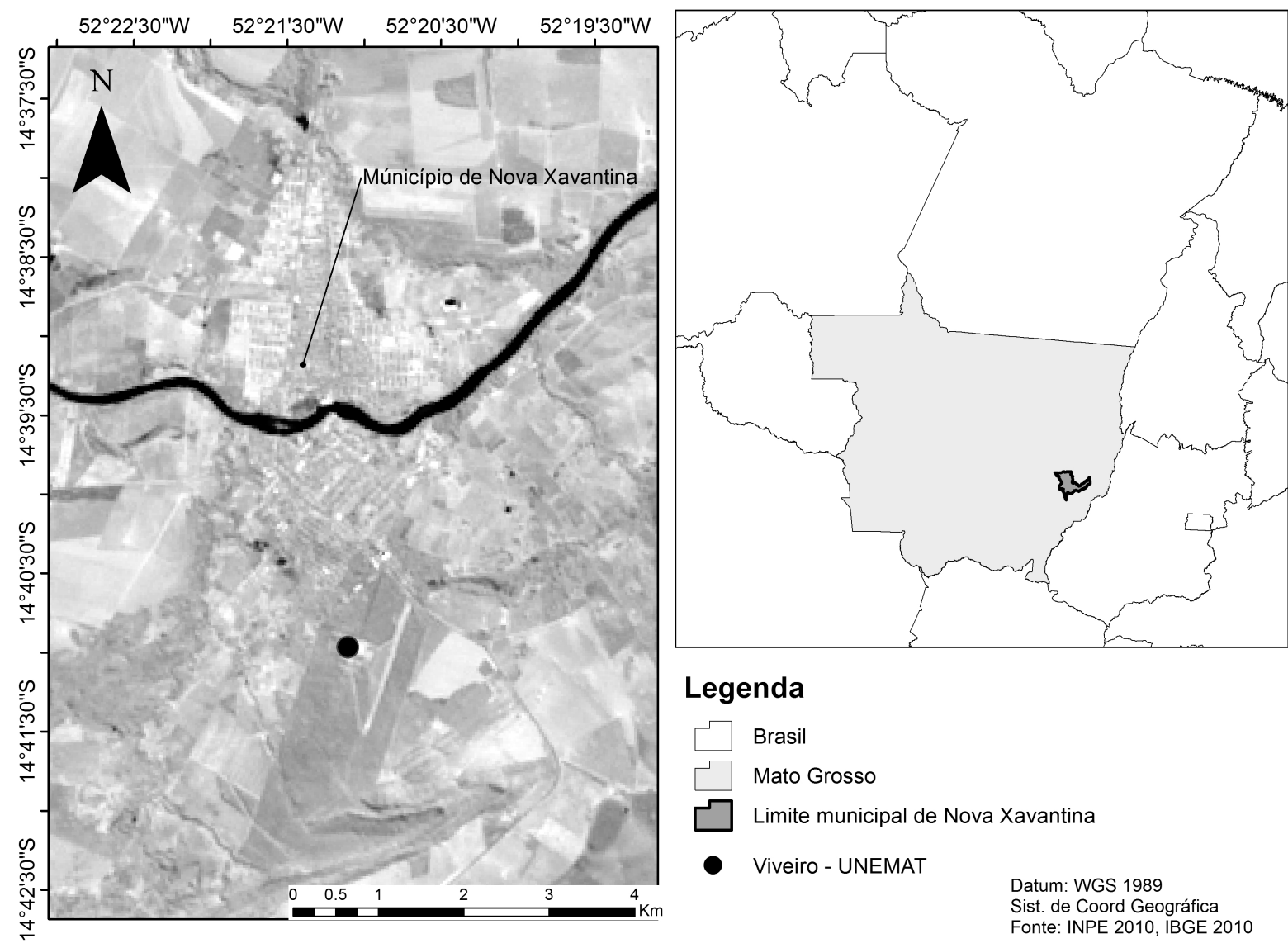

FIGURA 1. Localização da casa de vegetação da Unemat - Campus Universitário de Nova Xavantina - MT. Fonte: elaborado pelos autores.

Foram selecionadas sementes sadias de Annona squamosa $\mathrm{L}$. as quais foram submetidas a cinco processos de tratamento para a quebra de dormência: sendo, a) tratamento 1 - controle (sem nenhum método ativo para a quebra de dormência); b) tratamento 2 - imersão em água durante seis horas; c) - tratamento 3 - imersão em água por 24 horas; d) tratamento 4 - escarificação mecânica e; e) tratamento 5 imersão em ácido sulfúrico. Posteriormente a esses tratamentos, as sementes foram acondicionadas em cinco bandejas com 49 tubetes florestais cada (representando os cinco tratamentos). Cada tubete recebeu três sementes da Annona squamosa L. 
A partir da semeadura que ocorreu em 08/09/2015, após 60 dias, período este que se desenvolveu um trabalho de conclusão de curso sobre germinação, realizouse a coleta de sete indivíduos de cada tratamento, para esse trabalho sobre histologia, onde do tratamento 1 - coletou-se todos os indivíduos na linha 1 , tratamento 2 - coletou-se os indivíduos da linha 2, tratamento 3 - coletou-se da linha 3 , tratamento 4 - coletou-se da linha 4 , e tratamento 5 - coletou-se os indivíduos da linha 5.

Após a coleta do material vegetal, estes foram levados ao laboratório de microscopia, onde foram efetuados cortes histológicos a mão livre do caule dos indivíduos, com auxílio de lâmina de barbear. Foram feitos cortes a $4 \mathrm{~cm}$ acima do coleto, depois foram lavados em água destilada e corados com azul de metileno a $50 \%$, de acordo com PEREIRA et al. (2003). Os cortes foram analisados em microscópio óptico (ZEISS-JENEMED2), com aumento de 40 vezes, com as imagens capturadas com câmera SAMSUNG (GT-19300), no Laboratório de microscopia, da UNEMAT - Campus de Nova Xavantina - MT.

Em seguida, foi trabalhada uma imagem de cada indivíduo, o que totalizou sete imagens para cada tratamento. A partir dessas imagens foram feitas análises descritivas quantificando o número de camadas de células e o formato dessas células compondo a região de córtex e de medula de um indivíduo de cada tratamento, usando para essa avaliação uma imagem de cada tratamento, sendo que essa imagem foi escolhida aleatoriamente dentre as sete de cada tratamento. Também foi realizada análise quantitativa, onde se mensurou a espessura das regiões de córtex e medula dos caules, por meio das sete imagens de cada tratamento, usando o programa Meazure 2.0 (COMPEAU \& HIGGINS, 1995) e, esses valores de espessura de cada tratamento foram comparados por meio de análises de variância (ANOVA, alfa $=0,05$ ) e teste a posteriore de Tukey utilizando 0 programa Assistat 7.7 beta (SILVA \& AZEVEDO, 2016).

\section{RESULTADOS E DISCUSSÃO}

Ao analisar a abordagem descritiva quanto ao número de camadas de células compondo região de córtex e medula e o formato de célula que os compõe, foi possível verificar que 0 indivíduo representativo do tratamento 1 apresentou 42 camadas justapostas no córtex de células com formatos retangulares e tamanhos variados, enquanto a região medular foi composta por 39 camadas de células com formas arredondadas e com tamanhos variados (Figura 2A).

O indivíduo do tratamento dois apresentou 22 camadas na região do córtex, com células menores e bem compactadas, e região medular com 52 camadas compostas por células de formas arredondadas e tamanhos similares (Figura 2B). Já o indivíduo do tratamento três possuia 21 camadas de células justapostas compondo a região cortical, com formas arredondadas e a região medular apresentou 39 camadas de células, sendo as da porção central maiores e com formas arredondadas, já as localizadas nas extremidades eram justapostas e menores (Figura 2C).

Para o indivíduo do tratamento quatro foi possível verificar o córtex formado por 29 camadas de células arredondadas e bem compactadas, mas com a presença de espaços vazios entre as camadas, ou seja, a formação de aerênquima, enquanto que a região medular estava formada por 44 camadas de células, sendo as células presentes no centro com formatos irregulares e as das extremidades com formato arredondado (Figura 2D). 
O indivíduo analisado do tratamento cinco possuia córtex com 19 camadas de células arredondadas, com espaços vazios bem visíveis, formando aerênquima nessa região, já a medula era composta por 32 camadas com células arredondadas de tamanhos reduzidos, onde as células da porção mais central apresentavam formatos irregulares e diferentes tamanhos (Figura 2E).
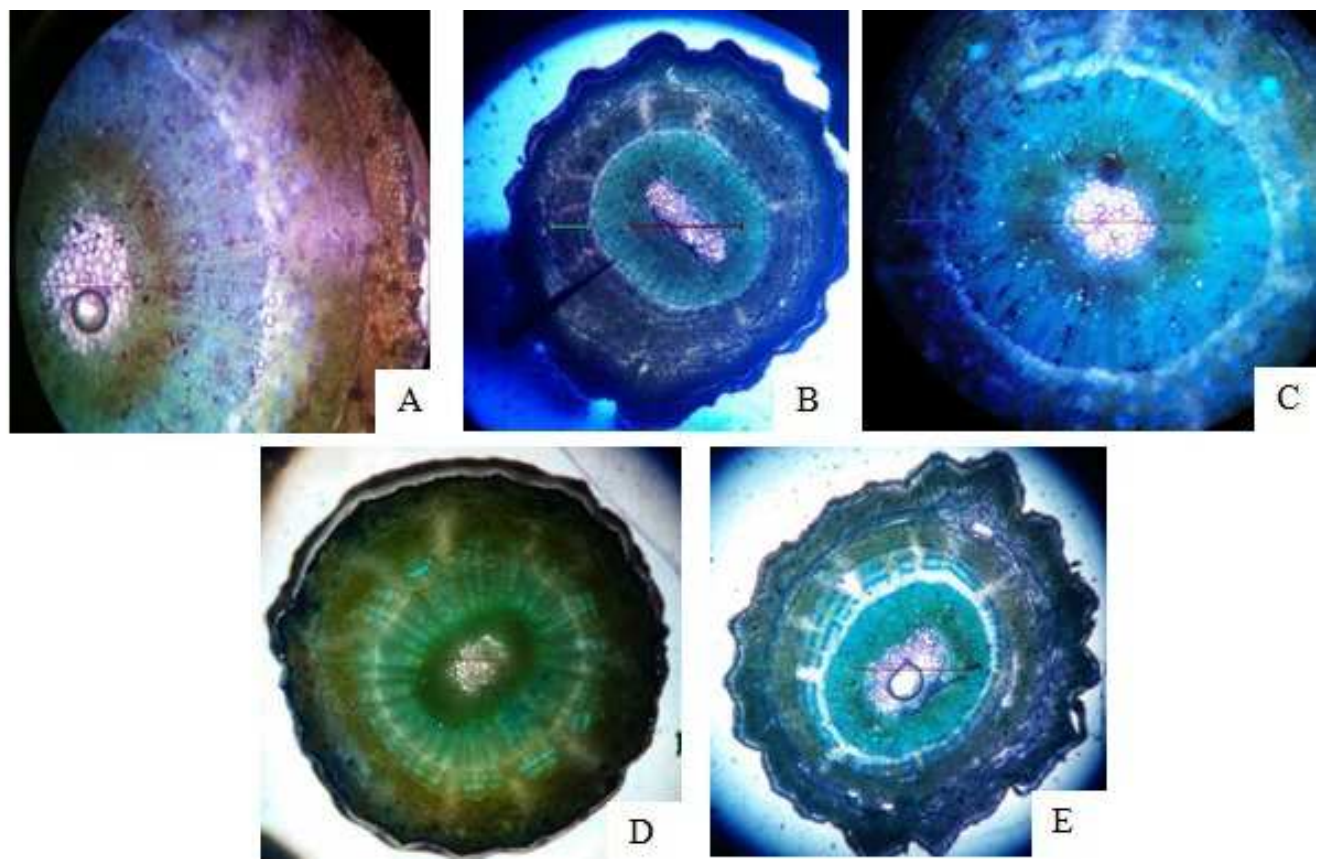

FIGURA 2. Regiões de córtex e de medula caulinar de $A$. squamosa $\mathrm{L}$. analisados quanto ao número de camadas e formatos de células. Em: A) tratamento 1 - controle; B) tratamento 2 imersão em água durante 6 horas; C) tratamento 3 - imersão em água por 24 horas; D) tratamento 4 - escarificação mecânica e; E) tratamento 5 - imersão em ácido sulfúrico. Fonte: elaborado pelos autores.

Essa variação na descrição do formato celular e no número de camadas de células entre as regiões de córtex e medula, quando comparados os tratamentos, está relacionada à individualidade analisada, pois se tratou de indivíduos diferentes, desta forma ao serem expostos aos métodos de superação de dormência, houve uma adaptação de caracteres histo-anatômicos (REEVE \& SHERMAN, 1993), sob ação de controladores ambientais que influenciam na germinação (NASSIF et al., 1998).

Sob ação dos controladores observou-se modificações histo-anatômicas, como a formação de aerênquima nos indivíduos do tratamento quatro (escarificação mecânica) e cinco (imersão em ácido sulfúrico), o que reflete um alto espectro de plasticidade fenotípica da espécie (SANTIAGO \& PAOLI, 2007).

Quanto a espessura das regiões analisadas (córtex e medula), foi possível verificar que os embriões no interior das sementes submetidas a diferentes métodos de quebra de dormência, desenvolveram o crescimento em indivíduos jovens de forma a não apresentarem diferenças significativas quanto à espessura das regiões de córtex $(p: 0,09)$ e de medula $(p: 0,68)$, quando comparadas por meio das médias de cada tratamento (Tabela 1). 
TABELA 1. Valores médios de região de córtex e medula em caules de indivíduos de $A$. squamosa $\mathrm{L}$. em função de diferentes métodos de superação de dormência.

\begin{tabular}{lcc}
\hline Métodos de superação de dormência Região do Córtex Região da Medula \\
\hline Controle & 2.12 & 5.03 \\
Imersão (6h) & 1.75 & 4.57 \\
Imersão (24h) & 1.52 & 4.14 \\
Escarificação mecânica & 1.44 & 4.04 \\
Escarificação química (A.S. ${ }^{*}$ ) & 2.40 & 4.89 \\
\hline
\end{tabular}

*Ácido sulfúrico (A.S.).

Esse resultado ocorreu devido à dormência das sementes dessa espécie não ser tegumentar, e sim endógena. SOUZA et al. (2008) indicam que apesar da espécie apresentar as sementes com tegumento rígido, a dormência da espécie não é devido a impermeabilidade do tegumento a água. WAGNER JÚNIOR et al. (2005) analisando a influência do tempo de embebição em água na superação da dormência e FERREIRA et al. (2002) avaliando a curva de embebição de sementes dessa espécie, notaram que não houve impedimento físico a entrada de água, citando que essa espécie possivelmente possui dormência endógena.

Segundo CARVALHO \& NAKAGAWA (2000) a água é o principal fator que influência no processo de germinação, já que quanto maior a quantidade de água disponível para as sementes, mais rápida será a absorção. Por meio do fornecimento da água, sucede a reidratação dos tecidos, resultando na intensificação das atividades fisiológicas, que culminam com o fornecimento de energia e nutrientes indispensáveis para o desenvolvimento do eixo embrionário.

Se o tegumento rígido da semente de $A$. squamosa L. não impede a entrada de água na amêndoa e consequentemente a hidratação do embrião (SOUZA et al., 2008), todos os tratamentos a partir do momento que passaram a receber água, periodicamente durante o experimento, proporcionaram o mesmo desenvolvimento aos embriões do interior das diferentes sementes.

Desta forma a não diferença significativa entre a espessura das regiões de córtex e medula dos caules de $A$. squamosa $\mathrm{L}$. entre os tratamentos pode indicar que, apesar dos métodos aos quais as sementes foram submetidas para a quebra da dormência do embrião, esses embriões estabeleceram os tecidos de revestimento, preenchimento, sustentação e vascularização que compõem essas regiões e, a espessura nesse desenvolvimento inicial pode ter sido influenciada por fatores abióticos controladores, aos quais todos os indivíduos estavam expostos, como quantidade de água, horário da irrigação, tipo de substrato e quantidade e horas de insolação, o que contribuiu com uma homogeneização do crescimento dos indivíduos. Isto ocorreu devido a resposta das plantas aos fitorreguladores dependentes de fatores genéticos e ambientais (VASCONCELOS et al., 2015), que influenciam diretamente no nível endógeno de hormônios nas plantas (AGUSTÍ \& ALMELA, 1991). 


\section{CONCLUSÃO}

Apesar dos métodos para superar a dormência do embrião, todos os indivíduos jovens vão estabelecer os tecidos básicos para o crescimento, sendo que, fatores ambientais e endógenos da espécie podem atuar como reguladores do crescimento inicial, proporcionando uma homogeneização na espessura das regiões de córtex e medula entre os indivíduos de uma mesma espécie.

\section{REFERÊNCIAS}

AGUSTÍ, M.; ALMELA, V. Aplicación de fitorreguladores en citricultura. Editora Aedos: Barcelona, 1991, 169p.

ATAÍDE, G. M.; BICALHO, E. M.; DIAS, D. C. F. S.; CASTRO, V. O.; ALVARENGA, E. M. Superação de dormência das sementes de Delonix regia (Bojer ex Hook.) Raf. Revista Árvore, Viçosa, v. 37, n. 6, p.1145-1152, 2013.

BAGATIM, A, G, NACATA, G.; ANDRADE, R. A. Efeito de tratamentos para quebra de dormência das sementes na emergência de gravioleira. Interciência, v. 41, n. 9, p. 629-632, 2016.

BATAGLION, G. A.; SILVA, F. M. A.; EBERLIN, M. N.; KOOLEN, H. H. F. Determination of the phenolic composition from Brazilian tropical fruits by UHPLCMS/MS. Food Chemistry, v. 180, p. 280-287, 2015.

BRAGA SOBRINHO, R. Produção integrada de Anonáceas no Brasil. Revista Brasileira de Fruticultura, Jaboticabal-SP, v. 36 n. especial, p. 102-107, 2014.

CARVALHO, N. M.; NAKAGAWA, J. Sementes: ciência, tecnologia e produção. Editora Funep: Jaboticabal, 2000, 588p.

CUNNINGHAM, S. A. Effects of habitat fragmentation on the reproductive ecology of four plant species in Mallee woodland. Conservation Biology, v. 14, n. 3, p.758768, 2000.

CAMPOS, L. F. C.; ABREU, C. M. D.; GUIMARÃES, R. N.; SELEGUINI, A. Scarification and gibberellic acid on emergence and seedling growth of Biriba. Ciência Rural, Santa Maria-RS v. 45, n. 10, p. 1748-1754, 2015.

COMPEAU, D. R.; HIGGINS, C. A. Computer self-efficacy: Development of a measure and initial test. MIS Quarterly, 19:2, p. 189-211,1995.

FERREIRA, G.; ERIG, P. R.; MORO E. Uso de ácido giberélico em sementes de fruta-do-conde (Annona squamosa L.) visando à produção de mudas em diferentes embalagens. Revista Brasileira de Fruticultura, n. 24, n.1, p.178-182, 2002. Disponível em: http://dx.doi.org/10.1590/S0100-29452002000100039. DOI: $10.1590 /$ S0100-29452002000100039

FREITAS, A. R.; LOPES, J. C.; MATHEUS, M. T.; MENGARDA, L. H. G.; VENANCIO, L. P.; CALDEIRA, M. V. W. Superação da dormência de sementes de jatobá. Pesquisa Florestal Brasileira. Pesquisa florestal brasileira, v. 33, n. 73, p. ENCICLOPÉDIA BIOSFERA, Centro Científico Conhecer - Goiânia, v. 14 n.25; p.388 
85-90, 2013. Disponível em: http://dx.doi.org/10.4336/2013.pfb.33.73.350. DOI: 0.4336/2013.pfb.33.73.350

GALINDO, E. A.; ALVES, E. U.; SILVA, K. B.; BARROZO, L. M.; MOURA, S. S. S. Germinação e vigor de sementes de Crataeva tapia L. em diferentes temperaturas e regimes de luz. Revista Ciência Agronômica, v. 43, n. 1, p. 138-145, 2012. Disponível em: http://dx.doi.org/10.1590/S1806-66902012000100017. DOI: 10.1590/S1806-66902012000100017.

LEMOS, E. E. P. A produção de anonáceas do Brasil. Revista Brasileira de Fruticutura, v. 36, p. 77-85, 2014.

MENEGAZZO, M. L.; OLIVEIRA, A. C.; KULCZYNSKI, S. M.; SILVA, A. E. Efeitos de métodos de superação de dormência em sementes de pinha (Annona squamosa L.). Revista Agrarian, v. 5, p. 29-35, 2012.

MENEGAZZO, M. L.; KULCZYNSK, S. M.; OLIVEIRA, A. C.; SILVA, E. A. Produção de mudas de pinha em diferentes recipientes utilizando métodos de superação de dormência em sementes. Revista Agrarian, Dourados-MS, v. 6, n. 20, p. 121-129, 2013.

NASSIF, S. M. L.; VIEIRA, I. G.; FERNADES, G. D. Fatores Externos (ambientais) que Influenciam na Germinação de Sementes. Piracicaba: IPEF/LCF/ESALQ/USP, Informativo Sementes IPEF, Abr-1998. 1998. Disponível em: <http:// www.ipef.br/tecsementes/germinacao.asp. Acesso em: 14/fev/2016.

NETO, A. C. A.; ARAÚJO, P. C.; MOREIRA, E. S. Germinação e vigor de sementes de pinha (Annona squamosa L.) de diferentes procedências. Enciclopédia Biosfera, v.9, n.17, p.1548-1555, 2013.

NETO, A. F.; DANTAS, B. F.; ALMEIDA, F. A. C.; LIMA, M. S.; SILVA, F. F. S. Influência da embalagem e do local de armazenamento na qualidade fisiológica de sementes de abóbora 'jacarezinho' (Curcubita moschata Duch). Revista Engenharia na Agricultura, Viçosa-MG, v. 22, n. 4, p. 294- 305, 2014.

PEREIRA, Z. V.; MEIRA, R. M. S. A.; AZEVEDO, A. A. Morfoanatomia foliar de Palicourea longepedunculata Gardiner (RUBIACEAE). Revista Árvore, n. 27, p. 759-767, 2003. Disponível em: <http://dx.doi.org/10.1590/S010067622003000600002>. doi: 10.1590/S0100-67622003000600002.

RAVEN, H. P.; EVERT, R. F.; EICHHORN, S. E. Biologia Vegetal. Editora Guanabara Koogan: Rio de Janeiro, 2014, 876p.

REEVE H. K.; SHERMAN, P. W. Adaptation and the goals of evolutionary research. Quarterly Review of Biology, v. 68, p.1-32, 1993.

RIZZINI, C. T. Tratado de fitogeografia do Brasil: aspectos ecológicos, 
sociológicos e florísticos. Editora Âmbito Cultural: São Paulo,1997, 747p.

SANTIAGO, E. F.; PAOLI, A. A. S. Respostas morfológicas em Guibourtia hymenifolia (Moric.) J. Leonard (Fabaceae) e Genipa americana L. (Rubiaceae), submetidas ao estresse por deficiência nutricional e alagamento do substrato. Revista Brasileira de Botânica, n.30, p.131-140, 2007. Disponível em: <http://dx.doi.org/10.1590/S0100-84042007000100013>. $\quad$ DOI: $10.1590 / S 0100-$ 84042007000100013

SANTOS, J. F.; LUZ, I. S,; MATSUMOTO, S. N.; D'ARÊDE, L. O; VIANA, A. E. S. Superação da dormência tegumentar de sementes de Piptadenia viridiflora (kunth) benth pela escarificação química. Bioscience Journal, v. 30, n. 6, p. 1642-1651, 2014.

SÃO JOSÉ, A. R.; PIRES, M. M.; FREITAS, A. L. G. E.; RIBEIRO, D. P.; PEREZ, L. A. A. Atualidades e perspectivas das Anonáceas no mundo. Revista Brasileira de Fruticultura, Jaboticabal-SP, v. 36, n. especial, p. 86-93, 2014.

SILVA, F. A. S.; AZEVEDO C. A. V. Comparison of means of agricultural experimentation data through different test using the software Assistat. African Journal Agricultural Research, v. 11(37), p. 3527-3531, 15 Sept/2016. DOI: 10.5897/AJAR2016.11523

SOUZA, A. S.; DANTAS, A. C. V. L, PELACANI C. R.; VIEIRA, E. L.; LEDO, C. A. S. Superação da dormência em sementes de pinha. Revista Verde, n. 21, p.118-121, 2008.

TAIZ, L.; ZEIGER, E. Fisiologia vegetal. 5. ed. Porto Alegre: ArtMed, 2013. 954p.

VASCONCELOS, L. H. C.; VENDRUSCULO, E. P.; VASCONCELOS, R. F.; SANTOS, M. M.; SELEGUINI, A. Utilização de métodos físicos e de fitorreguladores para superação de dormência em sementes de pinha. Revista de Agricultura Neotropical, v. 2, n. 4, p. 20-24, 2015.

WAGNER, J. A., ALEXANDRE, R. S., NEGREIROS, J. R. S.; PARIZZOTTO, A.; BRUCKNER, C. Influência da escarificação e do tempo de embebição das sementes sobre a germinação de maracujazeiro (Passiflora edulisf. flavicarpa Degener). Revista Ceres, n. 52, p. 369-378, 2005. 